\title{
Clinical and Virologic Characteristics of HIV-1 Positive Patients with Delta Hepatitis
}

\author{
Morsica $\mathbf{G}^{1 *}$, Peano $\mathrm{L}^{2}$, Bagaglio $\mathrm{S}^{1}$, Poli $\mathrm{A}^{1}$, Hasson $\mathrm{H}^{1}$, Messina $\mathrm{E}^{1}$ and Uberti-Foppa $\mathrm{C}^{3}$ \\ ${ }^{1}$ Division of Infectious Diseases, IRCCS, Ospedale San Raffaele, Milan, Italy \\ ${ }^{2}$ Mother-Child Department, Valley Regional Hospital, Aosta, Italy \\ ${ }^{3}$ Vita-Salute San Raffaele University, Milan, Italy
}

\begin{abstract}
Background and Aim: Hepatitis Delta Virus (HDV) infection has been mainly studied in HIV negative patients, while data on HIV-1 positive patients are limited. We investigated the virological pattern as well as biochemical and clinical features of liver disease and immune status in HIV-1 positive patients with delta hepatitis. Their clinical characteristics were compared with those of anti-HDV negative, hepatitis B surface antigen (HBsAg) positive/HIV+ patients.

Methods: This retrospective study included HBsAg positive subjects with anti-HDV serology available, during the period 2010-2017. Biochemical and virological parameters were obtained at last visit in 2017 for each patient. Potential determinants for HDV positivity were examined by applying multivariate regression model.

Results: Of $78 \mathrm{HBsAg}$ positive patients 19 (24.4\%) were found anti-HDV+. Anti-HDV+ patients were more frequently intra venous drug users, anti-HCV positive and HBV e antigen $(\mathrm{HBeAg})$ negative. Additionally, the patients had more severe liver disease and necro inflammatory activity (assessed by transient elastography and transaminases levels, repectively) than the counterpart of anti-HDV- patients. A suppressive effect of HDV over HCV was also revealed in anti-HDV+ subjects. By multivariate analysis, years of ART (OR 1.22; $\mathrm{Cl} 0.986-1.43, \mathrm{p}=0.014$ ) and sexual exposure vs. IVDU (OR 0.08; $\mathrm{Cl} 0.556-0.986, \mathrm{p}=0.004$ ) were independently associated with anti-HDV positivity.
\end{abstract}

Conclusion: Our data underlines the need for continuing prevention program that includes HBV vaccination, screening and monitoring in population at high risk, as well as development of an alternative treatment option for HDV.

Keywords: HBV; HDV; HCV; HIV-1; Replication; Fibrosis degree, Interaction

\begin{abstract}
Abbreviations: HDV: Hepatitis Delta Virus; HBsAg: Hepatitis B Surface Antigen; HBeAg: Hepatitis B e Antigen; ART: Antiretroviral Therapy; Anti HCV: Antibodies Against Hepatitis C Virus; 3TC: Lamivudine; FTC: Emtricitabine; TDF: Tenofovir; IQR: Interquartile Range; CI: Confidence Interval; ALT: Alanine Aminotransferase; AST: Aspartate Aminotransferase; OR: Odds Ratio; MSM: Men Who have Sex with Men; IVDU: Intravenous Drug Users
\end{abstract}

\section{Introduction}

Hepatitis D virus (HDV) or delta hepatitis is a defective single stranded RNA virus that requires hepatitis B surface antigen envelope (HBsAg) for replication and transmission [1]. HDV infection is more frequent in HBsAg positive HIV infected patients, than in the counterpart of HIV negative patients. Additionally, HDV infected patients are more likely persons who inject drugs and a positive hepatitis $\mathrm{C}$ virus (HCV) serology compared to HDV-uninfected ones [2,3]. Studies $[4,5]$ show that patients with double HBV and HDV infection have more severe liver disease, more rapid progression to cirrhosis and increased risk of hepatocellular carcinoma and decompensated liver cirrhosis. Thus, HDV infection represents an important health burden especially in high risk group of patients. However, there is only limited information on the clinical and virologic characteristic of Delta hepatitis in HIV-1 infected patients. Therefore, the aim of the present study was to investigate possible factors associated with delta hepatitis by evaluation of clinical and virologic characteristics in HBsAg+/HIV$1+$ patient with or without serological markers of delta hepatitis.

\section{Methods}

This retrospective observational study examined demographic, clinical, therapeutic information and laboratory data of HIV-1/HBsAg positive patients who were tested for anti-HDV between January 2010 and December 2017. Clinical data including biochemical parameters, immunological status, HIV-RNA, HBV-DNA, and serological markers of HBV infection were collected for each HIV-1 infected patient at last visit available in 2017. The degree of fibrosis was assessed by transient elastography and was considered the last measurement performed in 2017. HBV-DNA and HCV-RNA quantitative assays were performed by real time PCR [(Abbott diagnostics Illinois, USA) limit of sensitivity $10 \mathrm{IU} / \mathrm{mL}$, and $12 \mathrm{IU} / \mathrm{mL}$, respectively]. HDV-RNA qualitative assay was performed by home-made RT-PCR [6]. Briefly, total RNA was extracted from $200 \mu$ of each plasma sample using QIAamp Viral RNA kit (Qiagene, Hilden, Germany). After reverse transcription with outer antisense primer D3, $5 \mu \mathrm{L}$ cDNA was amplified with10 pmoles of outer primers encompassing the HDVAg of the HDV genome: outer sense primer D0, 5' AGTGGCTCTCCCTTAGCCAT-3'(nt 813-832); outer antisense D3, 5'- TGAACCCCCTCGAAGGTGGA-3'(nt 1147-1128); inner sense primer D1, 5'-GTCCTCCTTCGGATGCCCAG-3'(nt 847866); and inner antisense D2, 5'-GAGTCCCG-GAGTCCCCCTT-3'(nt

*Corresponding author: Giulia Morsica, Division of Infectious Diseases, IRCCS Ospedale San Raffaele, Milan, Italy via Stamira d'Ancona, 2020127 Milan, Italy, Tel: +390226437935; Fax: +390226437989; E-mail: morsica.giulia@hsr.it

Received August 16, 2018; Accepted November 21, 2018; Published November 28,2018

Citation: Morsica G, Peano L, Bagaglio S, Poli A, Hasson H, et al. (2018) Clinica and Virologic Characteristics of HIV-1 Positive Patients with Delta Hepatitis. J AIDS Clin Res 9: 782. doi: 10.4172/2155-6113.1000782

Copyright: @ 2018 Morsica G, et al. This is an open-access article distributed unde the terms of the Creative Commons Attribution License, which permits unrestricted use, distribution, and reproduction in any medium, provided the original author and source are credited. 
1084-1066). Nested PCR was performed on $2 \mu \mathrm{L}$ of the first amplification products as a template with $10 \mathrm{pmol}$ of the inner primer set.

In some cases the test was repeated at regular intervals. Patients previously treated with interferon or direct acting antivirals for $\mathrm{HCV}$ were excluded from this analysis. The data were retrieved from the database of the Division of Infectious Diseases of the San Raffaele Hospital (CSLHIV Cohort) Milan, Italy. The CSLHIV Cohort was approved by the ethics committee of the San Raffaele Hospital. At their first visit the patients provide written informed consent for scientific analyses of their data.

Results for continuous variables were reported as median [interquartile range (IQR)]. Characteristics of HIV-1 positive patients were compared using the Pearson's chi-square or Fisher's exact test for categorical variables and the Mann-Whitney test for continuous variables. Potential determinants for HDV positivity were examined by applying multivariate regression model. Independent variables have been included in the stepwise log-linear model when $\mathrm{p}<0.10$ and results were reported as odds ratios (OR) with their corresponding $95 \%$ confidence interval (CI). All statistical tests were two-sided at the 5\% level ( $\mathrm{p} \leq 0.05)$ and were performed using SPSS statistical software, version 22 (IBM SPSS Statistics, IBM Corporation, Chicago, IL, USA).

\section{Results}

Among 78 HBsAg+ HIV-1 infected patients tested for anti-HDV for whom were available clinical data, 59 were anti-HDV negative (HDV, 75.6\%) and 19 were anti-HDV positive (HDV+, 24.4\%). Clinical characteristics of HDV+ patients and HDV- patients are depicted in Table 1. By univariate analysis it was shown that the male gender was dominate between these two groups. Risk factor for HIV infection was differently distributed between HDV+ and HDV- patients. The HDV frequency was extremely high in intra venous drug users (IVDU) with respect to patients sexually exposed to the virus $(\mathrm{p}<0.001)$. Concerning the liver disease activity, HDV+ patients had higher alanine amino transferase levels (ALT) than HDV- patients $(\mathrm{p}=0.021)$. Liver stiffness measured by transient elastography and expressed by kilopascal ( $\mathrm{KPa})$, resulted higher in anti-HDV+ subjects with respect to HDV- subjects $(\mathrm{p}=0.001)$. Similarly, a higher degree of fibrosis (assessed by transient elastography according to metavir score) was found in HDV+ patients when compared to HDV- $(\mathrm{p}=0.020)$. HDV+ patients were less often HBeAg positive than HDV- patients (5.9\% and $43.6 \%$, respectively, $\mathrm{p}=0.004$ ). No difference in HIV-RNA and HBV-DNA (evaluated by qualitative and quantitative assays) was found between these two groups. Of note, all patients except one were exposed to ART including drugs against HIV/HBV [lamivudine (3TC), emtricitabine (FTC) or FTC plus tenofovir (TDF)]. Antibodies against HCV (anti-HCV) were more frequently detected in HDV+ than in HDV- patients $(68.4 \%$ and $22.0 \%$, of anti-HCV positivity respectively, $\mathrm{p}<0.001)$. On the contrary, HCV-RNA was more frequently found positive in HDV- than in $\mathrm{HDV}+$ patients (HCV-RNA was detectable in $53.8 \%$ of anti-HCV+/ anti-HDV- and $7.7 \%$ of anti-HCV+/anti-HDV+ subjects, $\mathrm{p}=0.030)$. In anti-HCV+ patients with undetectable HCV-RNA, data on HCV-RNA were retrieved from clinical records and confirmed negative in a mean of 6 (range 2-9) consecutive specimens.

HDV-RNA qualitative assay was available in 7/19 anti-HDV+ patients and was positive in $4 / 7$ (57.0\%) patients. In 3 patients found HDV-RNA positive, the assay was repeated in 3 subsequent serum

\begin{tabular}{|c|c|c|c|c|}
\hline Variables & Overall & $\begin{array}{c}\text { HDV+ } \\
\text { No pts=19 }\end{array}$ & $\begin{array}{c}\text { HDV- } \\
\text { No pts }=59\end{array}$ & p-value \\
\hline Gender males/females & $71 / 7$ & $17 / 2$ & $54 / 5$ & 1.000 \\
\hline Age & $51.0(48.0-55.3)$ & $53.0(50.0-55.0)$ & $51.0(46.0-56.0)$ & 0.151 \\
\hline $\begin{array}{l}\text { Risk factor for HIV-1 } \\
\text { IVDU/sexual/unknown }\end{array}$ & $17 / 39 / 22$ & $11 / 4 / 4$ & $6 / 35 / 18$ & $<0.001$ \\
\hline Years of HIV infection & $21.2(14.4-27.8)$ & $25.5(23.0-30.5)$ & $18.5(11.5-25.7)$ & 0.002 \\
\hline Years of ART & $17.0(9.1-20.7)$ & $20.6(16.9-23.7)$ & $14.7(7.3-19.4)$ & $<0.001$ \\
\hline CD4 T cells number $/ \mathrm{mm}^{3}$ & $698(426-857)$ & $535(245-854)$ & $750(482-867)$ & 0.151 \\
\hline $\mathrm{ALT}^{\circ} \mathrm{IU} / \mathrm{L}$ & $34(26-56)$ & $51(28-88)$ & $32(22-46)$ & 0.021 \\
\hline Transient elastography (KpA) & $\begin{array}{c}\text { No. pts }=58 \\
7.2(4.6-11.7)\end{array}$ & $\begin{array}{c}\text { No. pts=18 } \\
9.6(7.2-14.1)\end{array}$ & $\begin{array}{l}\text { No. pts }=40 \\
5.9(3.8-8.3)\end{array}$ & 0.001 \\
\hline $\begin{array}{c}\text { Fibrosis degree }^{\wedge} \\
\text { F0-F2 vs F3-F4 }\end{array}$ & $41 / 17$ & $9 / 9$ & $32 / 8$ & 0.020 \\
\hline HBeAg-pos/neg (N72) & $25 / 47$ & $1 / 16$ & $24 / 31$ & 0.004 \\
\hline HIV-RNA* Positive/Negative & $7 / 71$ & $3 / 16$ & $4 / 55$ & 0.352 \\
\hline HIV-RNA load, copies/mL & $164(60-5569)$ & $352(-)^{\#}$ & $112(59-4218)$ & 0.400 \\
\hline $\begin{array}{l}\text { HBV-DNA pos/neg } \\
\text { (N74) }\end{array}$ & $19 / 55$ & $\begin{array}{c}\text { No pts. }=17 \\
4 / 13\end{array}$ & $\begin{array}{c}\text { No pts. }=57 \\
15 / 42\end{array}$ & 1.000 \\
\hline HBV-DNA load IU/mL & $10(10-15)$ & $10(10-42)$ & $10(10-19)$ & 0.754 \\
\hline Anti-HCV pos/neg & $26 / 52$ & $13 / 6$ & $13 / 46$ & $<0.001$ \\
\hline HCV-RNA pos/neg & $8 / 18$ & $1 / 12$ & $7 / 6$ & 0.030 \\
\hline HCV-RNA load IU/mL & $114527(401-446430)$ & $173575(-)^{\# \#}$ & $55478(362-1830824)$ & 1.000 \\
\hline FTC or $3 T C / T D F+F^{\circ}{ }^{\circ \circ}$ & $12 / 65$ & $8 / 10$ & $4 / 55$ & 0.001 \\
\hline \multicolumn{5}{|c|}{$\begin{array}{l}\text { Abbreviations: IVDU: Intra Venous Drug Users; Pos: Positive; Neg: Negative; ALT: Alanine Aminotransfe } \\
\text { Results are expressed as median (interquartile range, IQR). P-values according to Mann Whitney test o } \\
{ }^{\circ} \mathrm{ALT} \text { (normal value }<35 \mathrm{IU} / \mathrm{L} \text { ) } \\
\text { ^Fibrosis degree was evaluated in patients for whom was available transient elastography } \\
{ }^{*} \mathrm{HIV}-\mathrm{RNA} \text { positive } \geq 50 \text { copies /mL } \\
\text { \#IQR was not calculated because only } 3 \text { patients had quantifiable HIV load among anti-HDV+ patients. } \\
\text { \#\#IQR was not calculated because only } 1 \mathrm{HDV}+\text { patient had a quantifiable HCV load. } \\
{ }^{\circ} \text { One patient did not receive any treatment. }\end{array}$} \\
\hline
\end{tabular}

Table 1: Characteristics of HIV-1/HBsAg positive patients with or without HDV. 
samples with an alternance of HDV-RNA positivity or negativity. Finally, HDV- patients were more frequently under ART regimen including 2 drugs against HIV/HBV than the counterpart of HDV+ patients $(6.8 \%$ vs. $44.4 \%$; $=0.001)$. By multivariate analysis, years of ART (OR 1.22; CI 0.986-1.43, $\mathrm{p}=0.014$ ) and sexual exposure vs. IVDU (OR 0.08; CI 0.556-0.986, $\mathrm{p}=0.004$ ) were independently associated with the risk to be anti-HDV positive. Finally, we evaluated the impact of $\mathrm{HCV}$ co-infection on the severity of liver disease in HDV+ patients. We found that anti-HCV positivity was not associated with a higher fibrosis score in $\mathrm{HDV}+$ patients (among $\mathrm{HDV}+/$ anti-HCV+, 4 patients had $\mathrm{F} 0$ F2 and 8 patients had F3-F4; among HDV+/anti-HCV-, 3 patients had F0-F2 and 3 other patients had F3-F4; $\mathrm{p}=0.626$ ).

\section{Discussion}

We found a high frequency (24.4\%) of anti-HDV positivity in HIV/HBsAg+ patients attending our Division of Infectious Diseases in Milan, Italy. By univariate analysis, we found that HDV+ patients were more frequently IVDU respect to anti-HDV- patients and had a longer duration of HIV infection as well as longer duration of ART respect to the counterpart of HDV-. Reports from Europe $[7,8]$ showed a lower prevalence of HDV infection in HIV-1 positive patients, while studies from Taiwan $[9,10]$ reported dramatically high prevalence of HDV among HIV-1 patients/IVDU. So, our data likely reflects the high proportion of IVDU as main risk factor among HDV+ subjects.

A previous study [11] showed that HDV+ patients had more severe liver disease when compared to HDV uninfected persons. Accordingly, we found that among individuals with available data concerning the fibrosis degree, 9/18 (50.0\%) HDV+ subjects had evidence of severe liver disease; while in HDV- patients only 8/40 (20.0\%) had fibrosis score between F3-F4. However, these patients had a longer duration of HIV infection that could justify the higher degree of fibrosis with respect to HDV- patients. However, these patients had also a longer duration of ART, when compared to those not infected by HDV that could be of benefit at least on double HIV/HBV infection.

Studies [12-14] showed that treatment with nucleoside or nucleotide analogues (NA) were not effective against HDV in HIV-1 negative/ HBsAg positive patients. Soriano et al. [15] showed that ART treatment including tenofovir (TDF) worked well in HIV/HBV/HDV triple infected patients. More recently, Béguelin et al. [16], showed no activity of TDF on HDV replication in HIV/HBV/HDV triple infection. In the present study we did not specifically investigate the effect of treatment with NA on HDV. However, our findings of more advanced liver disease and higher necroinflammatory activity (assessed by transient elastography and ALT levels, respectively) in HDV+ patients respect to HDV- patients, suggested that ART including NA was not effective on HDV. We found that in HDV+ patients, (who were more frequently anti-HCV positive) the fibrosis score was similar in HDV+/anti-HCV+ and HDV+/anti-HCV- patients, suggesting that the severity of liver disease was likely consequent to HDV infection "per se" rather than to $\mathrm{HDV} / \mathrm{HCV}$ co-infection.

Of note, the majority of HDV- patients had positivity for HBeAg, while near all $\mathrm{HDV}+$ patients were $\mathrm{HBeAg}$ negative. It is well known that the majority of HDV+ subjects in Europe are positive for anti$\mathrm{HBe}$ antibodies and negative for HBeAg. This phenomenon has been explained by epidemiological features, as HDV has mainly been studied in Mediterranean bassin, where most hepatitis B patients are HBeAg-negative $[17,18]$. However, our patients group (including HDV+ and HDV-patients) had the same geographic origin (data not shown). One other possibility for this finding is suppressive effect of HDV on HBV replication.
No difference in HBV-DNA levels or HBV-DNA qualitative assay was found between HDV + and HDV- patients. All these patients, apart from one, were under ART including drugs against HBV/HIV and the majority of patients had very low levels or undetectable HBV-DNA. Therefore, it was not possible to evaluate a suppressive effect of HDV on HBV replication. We also found a higher frequency of HCV infection assessed by anti-HCV positivity in HDV+ patients with respect to HDV- patients, this finding likely reflects the different efficiency of HCV transmission comparing IVDU vs. sexual exposure, which was consistent with previous studies $[10,11,19,20]$.

The complex interplay between multiple hepatitis infections has been described in previous reports which generally showed HDV to be the dominant virus leading to the suppression of HBV as well as of HCV [21-23]. Although we did not evaluate in all patients the presence of HDV-RNA, we showed that the majority of anti-HDV+ patients had a positive serology for HCV without evidence of HCV replicating virus. This finding suggests a strong inhibitory effect of HDV on HCV; however, the mechanism behind this inhibitory effect remains unknown. By multivariate analysis, the major determinants of HDV infection were IVDU and the years of ART. To the best of our knowledge, this is the first report showing an association between years of ART and HDV infection in HIV-1 subjects, suggesting that ART including or not drugs active on HIV/HBV is not protective against HDV infection. Longer duration of ART and concomitantly longer duration of HIV infection in HDV+ patients respect to HDV- patients may also reflect a longer period of exposure to the virus.

\section{Conclusion}

Our study was limited by the nature of cross-sectional investigation and small sample size. So, it is possible that a number of $\mathrm{HBsAg+}$ patients were not tested for anti-HDV or their data were not reported in the database. In addition, HDV-RNA assay was not performed in all anti-HDV positive patients. Therefore, we considered as HDV infected those patients with anti-HDV positivity. In summary, we compared clinical and virologic characteristics of $\mathrm{HBsAg}+$ patients with or without HDV, some of whom were also HCV coinfected. We confirmed the severity of liver disease by a non-invasive method for assessing liver fibrosis and added information on demographic, immunological and virologic features of HIV1-/HDV + patients, that could be taken in consideration for the management of this difficult to treat group.

\section{Conflict of Interest}

Morsica G, Peano L, Bagaglio S, Poli A, Hasson H, Messina M, Uberti-Foppa $C$ have declared that no competing interests exist.

\section{References}

1. Rizzetto M, Canese MG, Gerin JL, London WT, Sly DL, et al. (1980) Transmission of the hepatitis B virus-associated delta antigen to chimpanzees. $\mathrm{J}$ Infect Dis 141: 590e602.

2. Chang SY, Yang CL, Ko WS, Liu WC, Lin CY, et al. (2011) Molecular epidemiology of hepatitis $D$ virus infection among injecting drug users with and without human immunodeficiency virus infection in Taiwan. J Clin Microbiol 49 $1083 \mathrm{e} 9$

3. Hsieh MH, Wang SC, Hsieh MY, Huang CF, Yeh ML, et al. (2016) Hepatitis $D$ virus infections among injecting drug users with and without human immunodeficiency virus infection in Taiwan. Kaohsiung Journal of Medical Sciences 32: 526-530

4. Fernandez-Montero JV, Vispo E, Barreiro P, Sierra Enguita R, De Mendoza C, et al. (2014) Hepatitis delta is a major determinant of liver decompensation events and death in HIV infected patients. Clin Infect Dis 58: $1549 \mathrm{e} 53$.

5. Sheng WH, Hung CC, Kao JH, Chang SY, Chen MY, et al. (2007) Impact of hepatitis $D$ virus infection on the long-term outcomes of patients with hepatitis 
Citation: Morsica G, Peano L, Bagaglio S, Poli A, Hasson H, et al. (2018) Clinical and Virologic Characteristics of HIV-1 Positive Patients with Delta Hepatitis. J AIDS Clin Res 9: 782. doi: 10.4172/2155-6113.1000782

$B$ virus and HIV coinfection in the era of highly active antiretroviral therapy: A matched cohort study. Clin Infect Dis 44: 988 e95.

6. Morsica G, Bagaglio S, Cicconi P, Capobianchi MR, Pellizzer G, et al. (2009) Hepa I.C.o.N.A the Icona Foundation Study Groups. Viral interference between hepatitis $B, C$, and $D$ viruses in dual and triple infections in HIV-positive patients. J Acquir Immune Defic Syndr 51: 574-581.

7. Soriano V, Grint D, D'Arminio Monforte A, Horban A, Leen C, et al. (2011) Hepatitis delta in HIV-infected individuals in Europe. AIDS 25: 1987-1992.

8. Aguilera A, Trastoy R, Rodríguez-Calviño J, Manso T, De Mendoza C, et al. (2018) Prevalence and incidence of hepatitis delta in patients with chronic hepatitis B in Spain. Eur J Gastroenterol Hepatol 30: 1060-1062.

9. Chang SY, Yang CL, Ko WS, Liu WC, Lin CY, et al. (2011) Molecular epidemiology of hepatitis $D$ virus infection among injecting drug users with and without human immunodeficiency virus infection in Taiwan. J Clin Microbiol 49: 1083-1089.

10. Lin HH, Lee SS, Yu ML, Chang TT, Su CW, et al. (2015) Changing hepatitis $D$ virus epidemiology in a hepatitis $B$ virus endemic area with a national vaccination program. Hepatology 61: 1870-1879.

11. Béguelin C, Moradpour D, Sahli R, Suter-Riniker F, Luthi A, et al. (2017) Hepatitis delta-associated mortality in HIV/HBV-coinfected patients. J Hepatol 66: 297-303

12. Niro G, Ciancio A, Tillman H, Lagget M, Olivero A, et al. (2005) Lamivudine therapy in chronic delta hepatitis: a multicentre randomized-controlled pilot study. Aliment Pharmacol Ther 22: 227-232.

13. Wedemeyer H, Yurdaydin C, Dalekos G, Erhardt A, Yilmaz C, et al. (2011) Peginterferon plus adefovir versus either drug alone for hepatitis delta. N Engl J Med 364: 322-331.

14. Kabaçam G, Onder FO, Yakut M, Seven G, Karatayli SC, et al. (2012) Entecavir treatment of chronic hepatitis D. Clin Infect Dis 55: 645-650.
15. Soriano V, Vispo E, Sierra-Enguita R, Mendoza CD, Fernández-Montero JV, et al. (2014) Efficacy of prolonged tenofovir therapy on hepatitis delta in HIVinfected patients. AIDS 28: 2389-2394.

16. Béguelin C, Friolet N, Moradpour D, Sahli R, Suter-Riniker F, et al. (2017) Impact of tenofovir on hepatitis delta virus replication in the swiss human immunodeficiency virus cohort study. Clin Infect Dis 64: 1275-1278.

17. Heidrich B, Serrano BC, Idilman R, Kabaçam G, Bremer B, et al. (2012) HBeAgpositive hepatitis delta: virological patterns and clinical long-term outcome. Liver Int 32: 1415-1425.

18. Wranke A, Pinheiro Borzacov LM, Parana R, Lobato C, Hamid S, et al. (2018) Hepatitis Delta International Network.Clinical and virological heterogeneity of hepatitis delta in different regions world-wide: The Hepatitis Delta International Network (HDIN). Liver Int 38: 842-850.

19. Heidrich B, Deterding K, Tillmann HL, Raupach R, Manns MP, et al. (2009) Virological and clinical characteristics of delta hepatitis in Central Europe. J Viral Hepat 16: 883-894.

20. Gish RG, Yi DH, Kane S, Clark M, Mangahas M, et al. (2013) Coinfection with hepatitis $B$ and $D$ : Epidemiology, prevalence and disease in patients in Northern California. J Gastroenterol Hepatol 28: 1521-1525.

21. Mathurin P, Thibault V, Kadidja K, Ganne-Carrie N, Moussalli J, et al. (2000) Replication status and histological features of patients with triple $(B, C, D)$ and dual $(B, C)$ hepatic infections. J Viral Hepat 7: 15-22.

22. Jardi R, Rodriguez F, Buti M, Costa X, Cotrina M, et al. (2001) Role of hepatitis $B, C$, and $D$ viruses in dual and triple infection: Influence of viral genotypes and hepatitis $\mathrm{B}$ precore and basal core promoter mutations on viral replicative interference. Hepatology 34: 404-410.

23. Boyd A, Lacombe K, Miailhes P, Gozlan J, Bonnard P, et al. (2010) Longitudinal evaluation of viral interactions in treated HIV-hepatitis B co-infected patients with additional hepatitis C and D virus. J Viral Hepat 17: 65-76. 